\title{
Pemberdayaan Masyarakat tentang Penggunaan Obat Rasional Melalui Edukasi Gema Cermat dengan Metode CBIA di Kelurahan Dukuh Menanggal, Surabaya
}

\author{
Dewi Perwito Sari ${ }^{1)}$, Asti Rahayu ${ }^{2)}$ \\ ${ }^{1,2)}$ Program Studi Sarjana Farmasi, Universitas PGRI Adi Buana Surabaya \\ dewiperwito@unipasby.ac.id
}

\begin{abstract}
ABSTRAK: Gerakan Masyarakat Cerdas Mengunakan Obat (Gema Cermat) dicanangkan sebagai upaya bersama antara pemerintah dan masyarakat dalam rangka mewujudkan kepedulian, kesadaran, pemahaman,dan keterampilan masyarakat dalam menggunakan obat secara bijak dan rasional. Gema Cermat bertujuan untuk meningkatkan pemahaman kesadaran masyarakat tentang pentingnya penggunaan obat secara tepat dan benar. Pengetahuan tersebut jarang sekali dikuasai oleh masyarakat, oleh karena itu perlu dilakukan pemberdayaan masyarakat dalam rangka meningkatkan pengetahuan tentang penggunaan obat untuk diri sendiri. Salah satu metode yang dapat digunakan adalah Cara Belajar Insan Aktif (CBIA). Edukasi Gema Cermat dilakukan bersama warga Kelurahan Dukuh Menanggal dan dilaksanakan selama kurun waktu Juni-Juli 2019 dengan desain pra-experimental one-group pretest-posttest. Pengukuran pengetahuan tentang obat dilakukan dengan menggunakan kuesioner dan dianalisa dengan uji paired $T$ test menggunakan SPSS. Hasil analisis $\mathrm{p}=0,000<$ 0,005, menunjukkan adanya peningkatan wawasan, pengetahuan yang lebih baik terkait penggunaan obat rasional. Pemberian edukasi Gema Cermat terhadap masyarakat memberikan efek atau dampak positif bagi dunia kesehatan, khususnya pada sektor kesehatan masyarakat sehingga dapat dilanjutkan dan dikembangkan penyuluhan dengan edukasi Gema Cermat.
\end{abstract}

Kata kunci: Gema Cermat, CBIA, Penggunaan obat rasional

\begin{abstract}
The Smart Utilize Drugs Society Action (Gema Cermat) was implemented as a co-operation between the government and the Society in order to creating concern, awareness, understanding, and skill in using medicine wisely and rationally. Gema Cermat aims to increase public awareness of the importance for using drugs properly and correctly, increasing the capability of choosing, obtaining, using, storing, and eradicating drugs exactly and correctly, then increasing rational drugs used. The people need to be empowered in order to increase knowledgement about swa-medication. The activity was carried out with the residents of the Dukuh Menanggal and was carried out during the June-July 2019 period with a preexperimental one-group pretest-posttest design. Measurement of knowledge about drugs is done by using a questionnaire and analyzed by paired T test using SPSS. Results of the analysis $p=$ $0,000<0.005$, showed an increase in insight, better knowledge related to rational drug use. The provision of Gema Cermat to the society has a positive effect or impact on the world of health, especially in the public health sector so that it can be continued and developed counseling with meticulous Gema Cermat.
\end{abstract}

Keywords: Gema Cermat, CBIA, Rational drug use 


\section{PENDAHULUAN}

Swamedikasi merupakan proses pengobatan yang dilakukan sendiri oleh seseorang mulai dari pengenalan keluhan atau gejalanya sampai pada pemilihan dan penggunaan obat. Gejala penyakit yang dapat dikenali sendiri oleh orang awam adalah penyakit ringan atau minor illnesses sedangkan obat yang dapat digunakan untuk swamedikasi adalah obat-obat yang dapat dibeli tanpa resep dokter (Widayati, 2013)

Hasil Riset Kesehatan Dasar (Riskesdas) tahun 2013 menunjukkan 103.860 atau $35,2 \%$ rumah tangga menyimpan obat untuk swamedikasi. Dari 35,2\% rumah tangga yang menyimpan obat, $35,7 \%$ di antaranya menyimpan obat keras dan $27,8 \%$ menyimpan antibiotik. Adanya obat keras dan antibiotika untuk swamedikasi menunjukkan penggunaan obat yang tidak rasional. Terdapat $81,9 \%$ RT menyimpan obat keras dan $86,1 \%$ RT menyimpan antibiotika yang diperoleh tanpa resep. Hal ini memicu terjadinya masalah kesehatan baru, khususnya resistensi bakteri.

Agar swamedikasi dapat dilakukan dengan benar, masyarakat harus mampu mengetahui jenis obat yang diperlukan serta kegunaan dari obat tersebut. Selain itu, pelaku swamedikasi harus mampu mengetahui batas toleransi pengobatan sendiri yang dilakukan, efek samping obat yang dapat timbul dan kondisi seperti apa yang tidak diperbolehkan menggunakan obat tersebut.

Pengetahuan tersebut jarang sekali dikuasai oleh masyarakat, oleh karena itu perlu dilakukan pemberdayaan masyarakat dalam rangka meningkatkan pengetahuan tentang penggunaan obat untuk diri sendiri. Salah satu metode yang dapat digunakan adalah Cara Belajar Insan Aktif (CBIA). Melalui metode ini diharapkan masyarakat lebih aktif dalam mencari informasi mengenai obat yang digunakan. Dengan informasi tersebut dapat menjadi dasar pertimbangan pemilihan obat dan tidak sekedar percaya dengan promosi / iklan obat sehingga swamedikasi dapat tercapai secara optimal.

\section{PERMASALAHAN}

Berdasarhan hasil analisis situasi yang telah dilakukan, dapat ditarik kesimpulan permasalahan terkait obat dari mitra yang mendasari dilakukannya program pengabdian kepada masyarakat ini antara lain:

1. Warga Kelurahan Dukuh Menanggal melakukan pengobatan sendiri terlebih dahulu ketika mengalami gejala sakit

2. Kurangnya pemahaman dan pengetahuan tentang penggunaan obat yang tepat dan rasional. Diantaranya, warga mengkonsumsi obat bebas secara berlebihan.

3. Kurangnya pemahaman tentang cara menyimpan dan membuang obat dengan benar 


\section{METODE PELAKSANAAN}

Kegiatan pengabdian masyarakat ini dilakukan dengan metode Cara Belajar Insan Aktif (CBIA) yaitu cara pembelajaran yang menuntut para peserta untuk berperan aktif dengan mengamati secara langsung objek yang akan dipelajari. Pelaksanaan program ini dibagi menjadi 2 kegiatan,

\section{Kegiatan 1}

kegiatan ini dilakukan secara kelompok, dimana setiap kelompok terdiri dari 6-8 orang. 1 Paket obat dibagikan kepada tiap-tiap kelompok. Kelompok diminta:

1. Mengamati kemasan obat untuk:

a. Mengenali nama dagang.

b. Mengenali nama bahan aktif.

c. Mengenali Kekuatan bahan aktif.

d. Mengenali bahan utama dan tambahan pada obat kombinasi.

2. Mengelompokkan obat berdasarkan jenis bahan aktif bukan berdasarkan indikasi.

\section{Kegiatan 2}

Tahap kegiatan ini bertujuan agar peserta berlatih mencari informasi dari kemasan, dengan cara meneliti setiap tulisan yang tercantum dalam kemasan maupun package insert. Tahap ini merupakan kegiatan untuk mengumpulkan informasi yang diperlukan sebagai dasar melakukan self-medication, yaitu:

1. Nama bahan aktif,

2. Indikasi,

3. Aturan penggunaan,

4. Efek samping, dan

5. Kontraindikasi.

6. Kontraindikasi.

\section{PELAKSANAAN}

Pengabdian dilaksanakan di Gedung Fakultas Ilmu Kesehatan Universitas PGRI Adi Buana Suarabaya, melibatkan 26 orang warga kelurahan Dukuh Menanggal, Kecamatan Gayungan. Pelaksanaan pengabdian dilakukan bersama perwakilan organisasi profesi Ikatan Apoteker Indonesia (IAI), mitra Apotek dan tim dosen. Edukasi Gema Cermat dilaksanakan dalam 3 tahap, yaitu pretest, intervensi dengan metode CBIA dan posttest menggunakan kuesioner guna mengukur pengetahuan peserta terhadap penggunaan obat-obatan. 


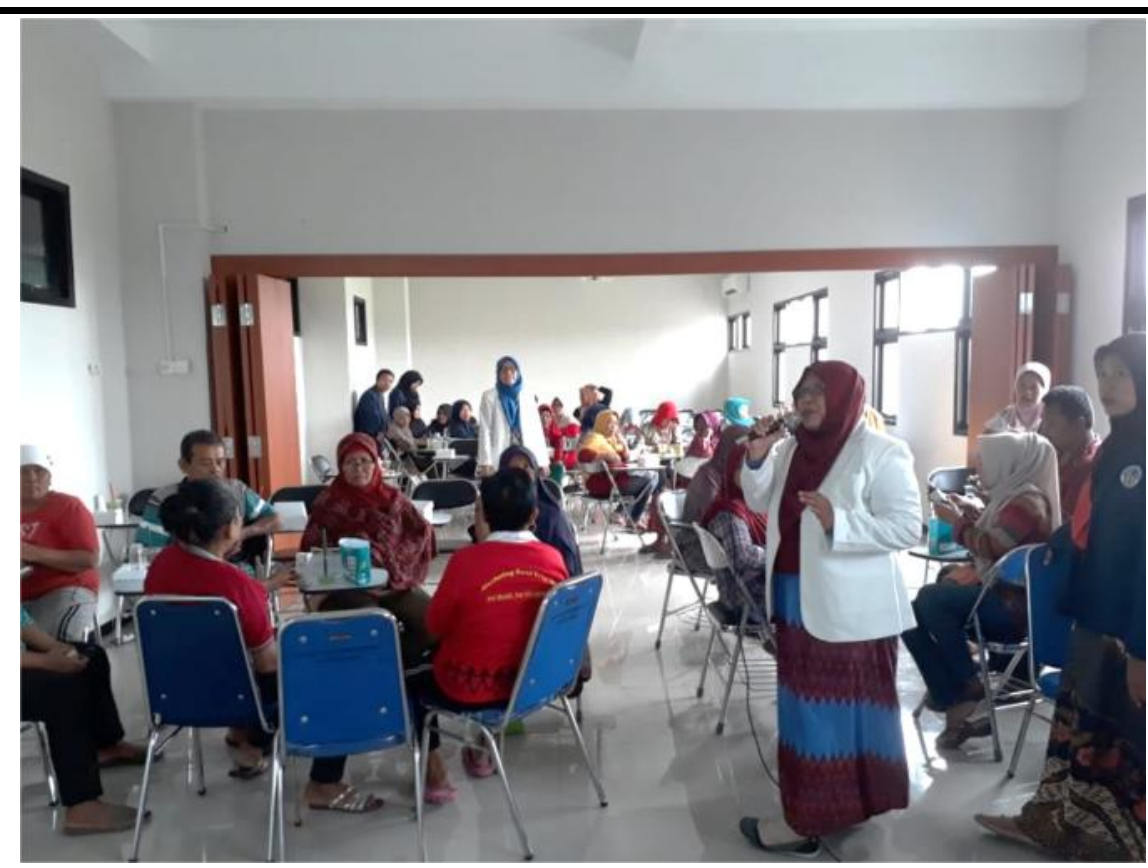

Gambar 1. Kegiatan 1: mengamati dan mengelompokkan obat

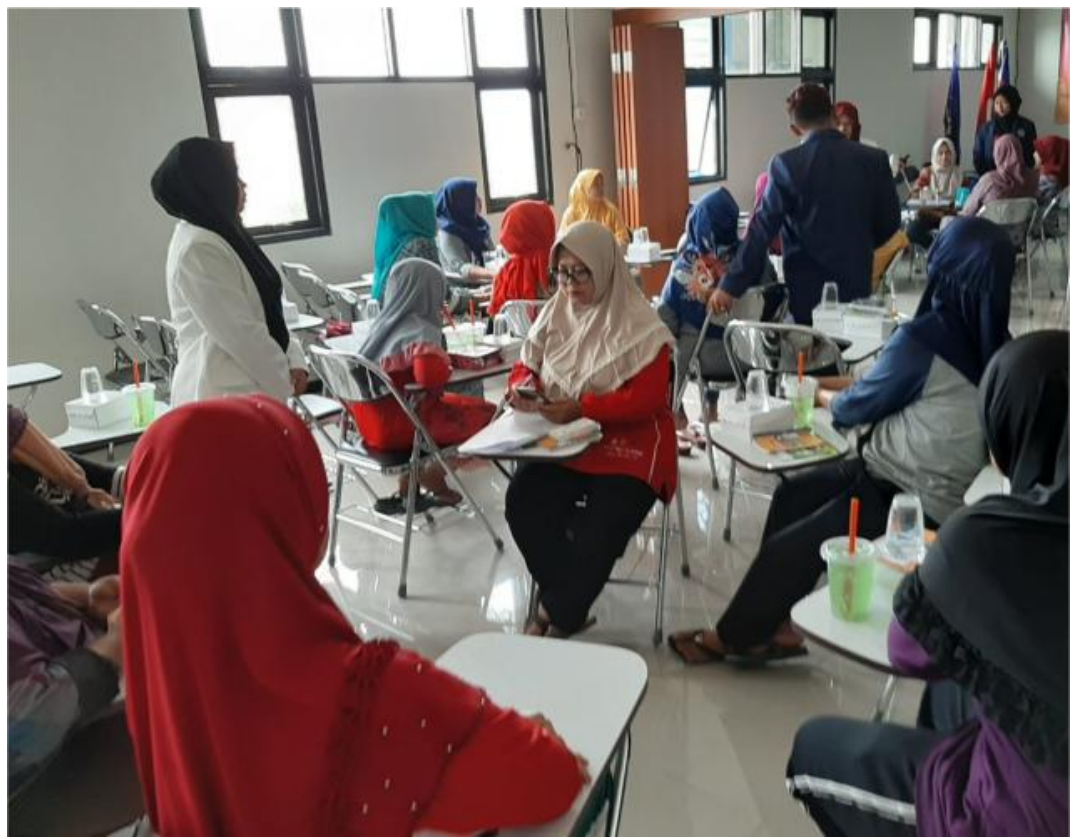

Gambar 2. Kegiatan 2: mencari informasi dari kemasan dan package insert 


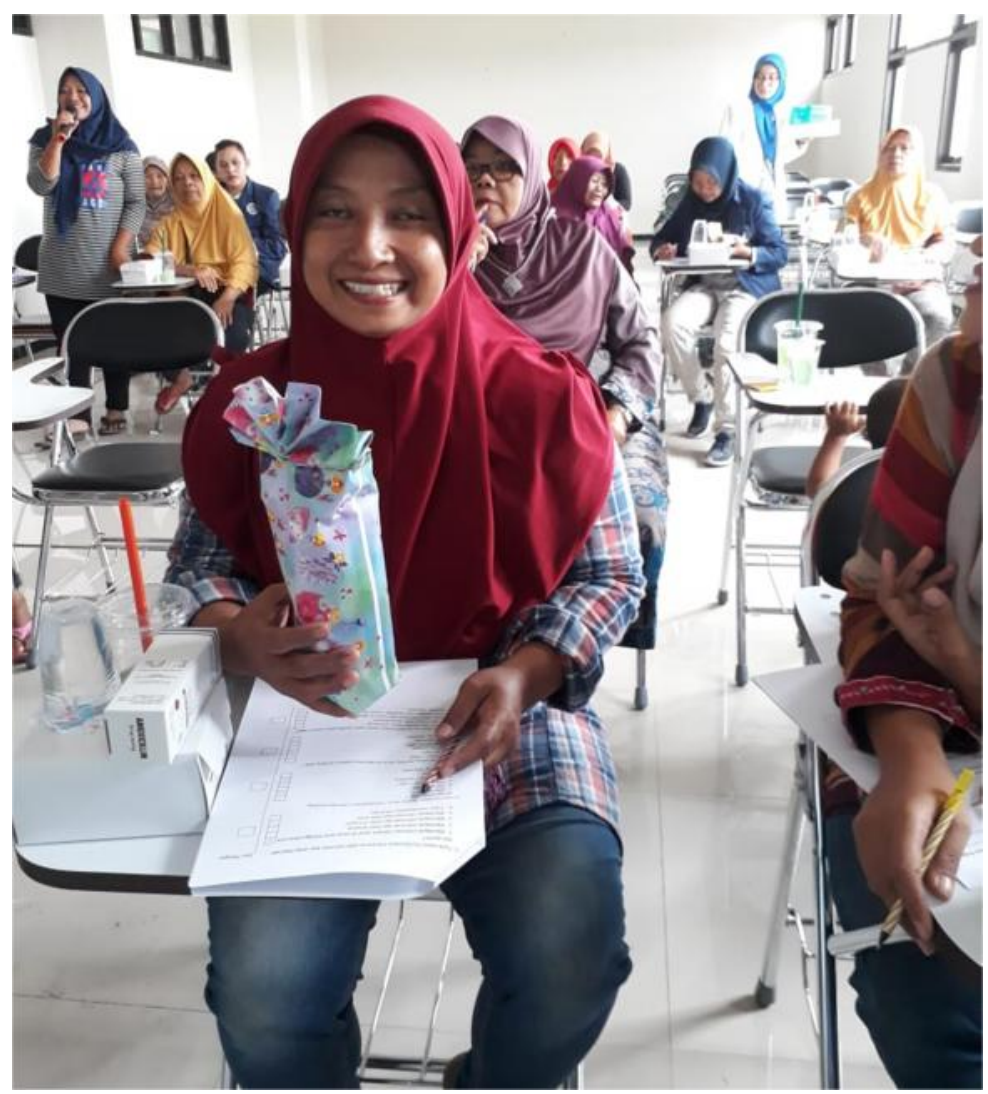

Gambar 3. Diskusi dan pengisian kuisioner

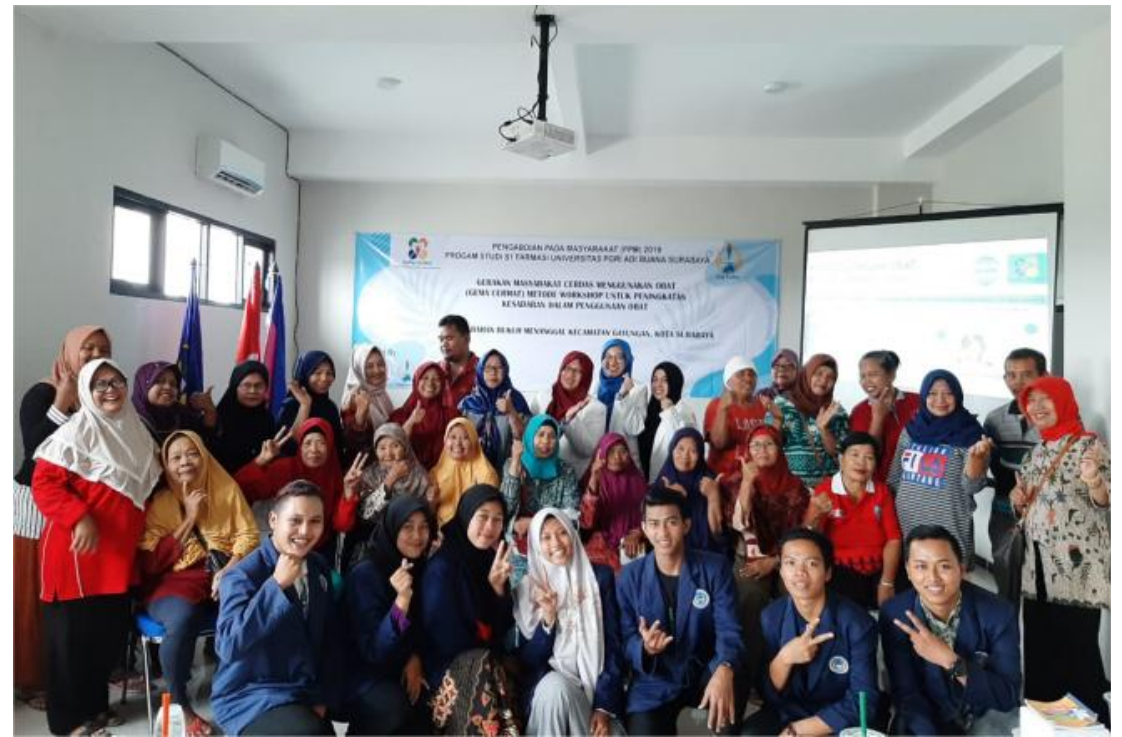

Gambar 4. Penutupan Kegiatan Pengabdian Kepada Masyarakat

HASIL DAN LUARAN

Peserta pengabdian merupakan warga di Kelurahan Dukuh Menanggal, Surabaya. Peserta berjumlah 26 orang dengan data seperti pada Tabel 1. 


\begin{tabular}{lcc}
\hline \multicolumn{2}{c}{ Table 1. Karakteristik demografi peserta } \\
\cline { 2 - 3 } Usia & Jumlah & Persentase \\
\hline $18-40$ tahun & 5 & \\
$41-75$ tahun & 21 & $19,2 \%$ \\
Pendidikan & & $80,8 \%$ \\
SD & 13 & \\
SMP & 2 & $50 \%$ \\
SMA & 9 & $7,69 \%$ \\
PT & 1 & $34,62 \%$ \\
Lainnya & 1 & $3,85 \%$ \\
Pekerjaan & & $3,85 \%$ \\
Pegawai negeri & 1 & \\
Pegawai swasta & 6 & $3,85 \%$ \\
Pedagang & 6 & $23,05 \%$ \\
IRT & 12 & $23,08 \%$ \\
Lainnya & 1 & $46,15 \%$ \\
\hline
\end{tabular}

Tabel 1 menunjukkan bahwa 80,8\% merupakan peserta dengan usia 41-75 tahun dan 19,2\% merupakan peserta dengan rentang usia 18-40 tahun. Tingkat Pendidikan peserta pun bervariasi, dimana 50\% berpendidikan Sekolah Dasar, 7,69\% Sekolah Menengah Pertama, 34,62\% Sekolah Menengah Atas, 3,85\% Perguruan Tinggi dan $3,85 \%$ lain-lain. Beberapa penelitian mengungkapkan adanya hubungan antara tingkat pendidikan dengan pengetahuan dan tindakan swamedikasi (Harahap, 2017).

Selanjutnya untuk pekerjaan diperoleh data 3,85\% Pegawai Negeri Sipil, 23,05\% Pegawai swasta, 23,08\% pedagang, 46,15\% Ibu Rumah Tangga dan 3,85\% lain-lain.

Edukasi Gema Cermat dilaksanakan dalam 3 tahap, yaitu pretest, intervensi dengan metode CBIA dan posttest menggunakan kuesioner guna mengukur pengetahuan peserta terhadap penggunaan obat-obatan. Pengetahuan peserta sebelum edukasi dan setelah edukasi dianalisa dengan uji paired $T$ test menggunakan SPSS. Berdasarkan hasil uji pretest dan posttest peserta diperoleh hasil sebagai berikut:

Tabel 2. Uji Paired T Test Pengetahuan Obat sebelum-sesudah edukasi

\begin{tabular}{cccc}
\multicolumn{3}{c}{ Gema Cermat } & \\
\hline & Mean & $\begin{array}{c}\text { Std } \\
\text { Deviasi }\end{array}$ & Sig. \\
\hline Sebelum-sesudah & $-5,423$ & 4,100 & 0,000 \\
\hline
\end{tabular}

Tabel 2 menunjukkan nilai $\mathrm{p}=0,000<0,005$ yang berarti bahwa terdapat hubungan atau pengaruh yang bermakna antara pemberian edukasi Gema Cermat dengan metode CBIA terhadap wawasan, pengetahuan dan keterampilan peserta terkait obat, dimana pengetahuan peserta mengalami peningkatan dari sebelum diedukasi hingga setelah diedukasi. 
Metode Cara Belajar Insan Aktif (CBIA) merupakan salah satu upaya pemberdayaan masyarakat yang tepat untuk edukasi terkait penggunaan obat yang rasional. Metode ini terbukti efektif untuk meningkatkan pengetahuan dan keterampilan peserta dalam pemilihan obat dan dapat meningkatkan efisiensi penggunaan obat dalam rumah tangga. Pemberian edukasi Gema Cermat terhadap masyarakat memberikan efek atau dampak positif bagi dunia kesehatan, khususnya pada sektor kesehatan masyarakat sehingga dapat dilanjutkan dan dikembangkan penyuluhan dengan edukasi Gema Cermat.

Sehubungan dengan data diatas maka luaran yang telah dicapai dari kegiatan Pengabdian Kepada Masyarakat ini adalah meningkatnya wawasan, pengetahuan dan keterampilan peserta dalam memilih dan menggunakan obat secara rasional. Secara khusus luaran yang dicapai setelah program ini terlaksana adalah:

1. Peningkatan wawasan, pengetahuan yang lebih baik terkait penggunaan obat rasional

2. Peserta mampu memahami penggunaan obat secara bijak dan pengelolaan terapi untuk diri sendiri

3. Peserta dapat menjadi kader dan melanjutkan kegiatan ini pada warga masyarakat lainnya.

\section{KESIMPULAN}

Berdasarkan hasil kegiatan edukasi Gema Cermat dengan metode CBIA ini dapat disimpulkan bahwa:

a) Edukasi gema cermat dengan metode CBIA dapat meningkatkan wawasan, pengetahuan dan keterampilan masyarakat tentang penggunaan obat khususnya swamedikasi.

b) Hasil analisis paired $\mathrm{T}$ tes $\mathrm{p}=0,000<0,005$, menunjukkan adanya peningkatan pengetahuan masyarakat tentang penggunaan obat melalui edukasi gema cermat metode CBIA.

c) Adanya peningkatan pengetahuan tentang penggunaan obat rasional peserta mampu memahami penggunaan obat secara bijak dan pengelolaan terapi untuk diri sendiri maupun keluarga.

d) Kegiatan bimbingan dapat dilanjutkan dan dilakukan para peserta baik secara langsung maupun tidak langsung guna memantau keberlanjutan manfaat edukasi gema cermat.

\section{DAFTAR PUSTAKA}

Departemen Kesehatan RI. 2008. Modul Peningkatan Pengetahuan dan Keterampilan Memilih Obat Bagi Tenaga Kesehatan. Jakarta: Departemen Kesehatan Republik Indonesia.

Harahap, N.A., Khairunnisa., \& Tanuwijaya, J. 2017. Pengetahuan Pasien dan Rasionalitas Swamedikasi di Tiga Apotek Kota Panyabungan. Jurnal Sains Farmasi dan Klinis, 3(2): 186-192 
Volume 4, Nomor 1, Maret 2020

Kementerian Kesehatan Republik Indonesia. 2013, Riset Kesehatan Dasar. Jakarta: Kementerian Kesehatan Republik Indonesia

PP IAI. (2014). Pedoman Pelaksanaan Gerakan Keluarga Sadar Obat, Pengurus Pusat Ikatan Apoteker Indonesia. Diakses tanggal 21 Juni 2018.

WHO. 1998. The Role of The Pharmacist in Self-Care and Self Medication. Geneva: World Health Organisation

Widayati, A. 2013. Swamedikasi di Kalangan Masyarakat Perkotaan di Kota Yogyakarta. Jurnal Farmasi Klinik Indonesia, 2(4): 145-152 